\title{
Learning Methodologies to Diffuse Lean Product Development to Industries
}

\author{
Monica Rossi ${ }^{1}$, Endris Kerga ${ }^{1}$, Marco Taisch $^{1}$, and Sergio Terzi ${ }^{2}$ \\ ${ }^{1}$ Politecnico di Milano, Department of Economics, Management and Industrial Engineering, \\ Piazza Leonardo da Vinci 32, Milano, 20133, Italy \\ \{monica.rossi, endris.kerga, marco.taisch\}@polimi.it \\ ${ }^{2}$ Università degli Studi di Bergamo, Department of Industrial Engineering Viale Marconi 5, \\ Dalmine (BG) 24044, Italy \\ sergio.terzi@unibg.it
}

\begin{abstract}
Every company strives to come-up with innovative products that satisfy customer requests efficiently and effectively. The principles and working methods of Lean thinking have been suggested in literature for companies to optimize stakeholders' interests throughout their product development (PD) process. However, the application of the Lean PD remains unclear from practitioner's perspective. As a consequence, there is a low level of awareness about it and its associated elements.

This paper first identifies and presents key challenges and gaps that exist to implement Lean PD in practice, using some of the results of a field study done in Italy. Then, learning methodologies that are developed to fill practical gaps will be presented along with the results achieved in terms of increasing awareness about lean product development.
\end{abstract}

Keywords: Lean Product Development, Product Development Wastes, SetBased Concurrent Engineering, Learning and Serious Games.

\section{Introduction to Lean Product Development (Lean PD)}

The complexity of a PD process makes it difficult to be monitored, streamlined, and standardized. The ever growing business dynamics pose challenges to effectively organize innovation process in such a way that the right customer value can be captured and delivered efficiently [1],[2]. Therefore, companies require equipping themselves with the right methodology to pace with the shift in the paradigm of managing product innovation process and keep ahead with the intense competition.

Toyota consistently developed higher quality vehicles faster than its competitors, for less costs and at a greater profit [3], [4]. It also launches more new vehicles annually than most of its competitors, creating a steady flow of high quality new products to meet consumer demand. This has fuelled industry leading profits, reaching a Japanese record of 10.9 billion dollars by 2005, a market capitalization greater than that of GM and Ford combined and a continuing growth in market share. Toyota has also achieved the lowest in the ratio of $\mathrm{R} \& \mathrm{D}$ cost to sales compared with its competitors [5]. 
Toyota's remarkable achievement can be attributed to a leaner and systematic approach it follows to manage PD [5], [6] and [7]. Figure 1 shows some of the elements of lean product development that are suggested in literature and are the interests of this paper. Each element will be briefly discussed below:

- Chief Engineer (CE) System: customer value research traditionally is a marketing activity based on surveys. The drawbacks of this approach are two. First, customers might not be explicit or might not be aware of what can potentially be offered to them. Second, customer value research and design process are disconnected in traditional PD. In contrast, in Lean PD it is the Chief Engineer who is responsible for investigating and defining customer values. CEs represent the customer throughout the development process, and ensure that program objectives and the goals among the cross-functional team are well aligned [8]. The classical project managers spent most of their time on administrative activities. In contrast, CEs at Toyota involve heavily in technical decisions and ideally are the most knowledgeable engineers. Therefore, such a strong project leader enables Toyota to understand the right customer values early and lead the development process effectively and efficiently [5], [6] and [7].

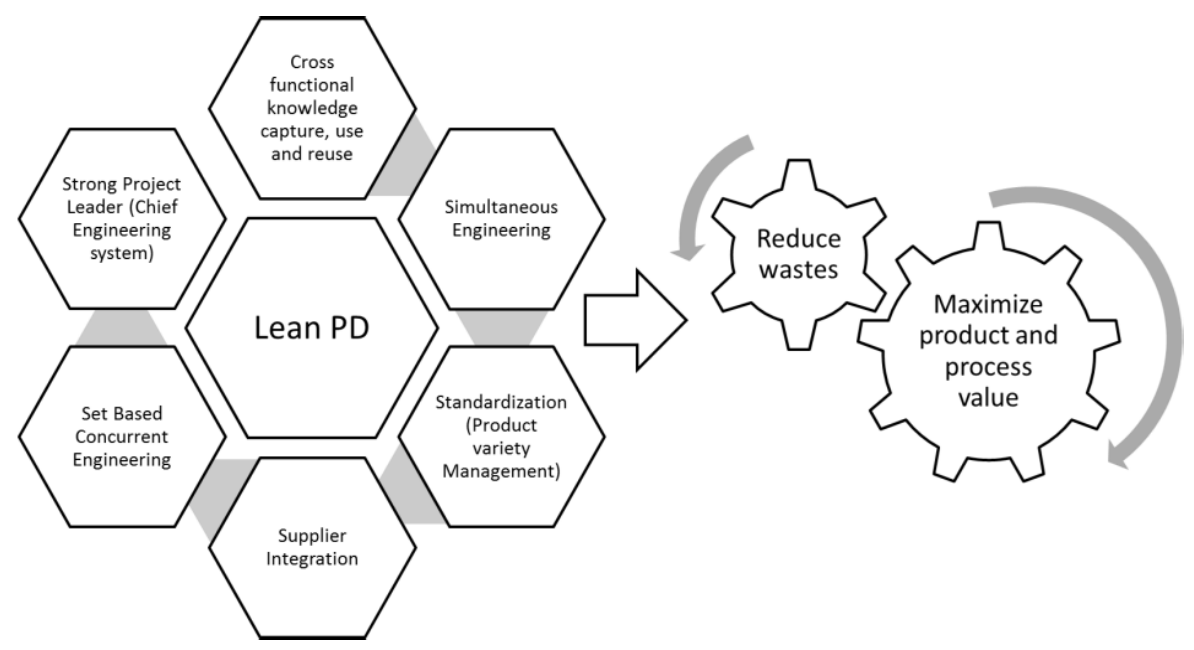

Fig. 1. Elements of Lean PD with the goal to minimize waste and maximize value

- Cross Functional Knowledge Capturing, Using and Reusing: effective management of knowledge in PD is critical. Since PD is a knowledge creation factory, organization should have in place the proper competencies and procedures to capture, use, document and reuse previous knowledge and lesson learned gained in a design process [5], [6]. Traditionally, PD projects are taken as independent, unrelated entities, and the knowledge gained in one project hardly is used in another. Toyota uses extensively the so called tradeoff and limit curves [5], [6]. The use of trade-off and limit curves allows to generalize and visualize knowledge to be effectively reused. And, strongly facilitate the integration of different functional domains throughout a project [9], [10]. 
- Simultaneous Engineering (SE): SE concerns with paralleling interdependent activities to reduce developed lead time and improve product quality. To improve the concurrency in PD, Toyota uses two mechanisms: Module Development Team (MDT) and Obeya room [5]. Once a concept paper with set of alternative solutions developed by CE the MDT breaks down the concept into technical details. Each MDT consists of one or more manufacturing engineering to investigate the manufacturability of the concepts developed [5]. The MDT team along with the manufacturing engineer/s investigates the alternative cost of manufacturing and assembly solutions to avoid late changes, as a consequence, cross functional knowledge sharing become a norm. In addition, Toyota has set up special rooms, called Obeya, which is used to hold regular meetings between designers, CEs and manufacturing engineers. This room facilitates the sharing of up-to-date or real time information and status about projects [5].

- Standardization and Reusing (Product Variety Management): a large variety of products, components or parts bring more complexity, inefficiencies and lower the possibility to use economies of scale and scope [9]. To deal with such tradeoffs, standardization and reusing previous modules have been suggested as Lean PD elements [9]. Toyota, for example, has a carry-over rate, i.e. percent reuse of components from a previous model to the successor, of about two third. Toyota is very cautious about introducing new technologies and tries to leverage their proven solutions from existing products as much as possible [11]. The strategy significantly reduces the time and cost of development.

- Supplier Involvement in PD: in automotive industry, about 70-80\% of all the parts are purchased from suppliers. Efforts made to improve PD efficiency and effectiveness should involve suppliers [5]. Traditionally, supplier selection is based on pure cost advantage. Suppliers fear to share details information to win bidding. This makes inevitable design rework once problems reveled late in a PD process. Japanese manufacturer use different strategy with their partner suppliers. They integrate their partners early in a design process to anticipate risks and capabilities [5]. This relationship brings cost reduction and improves other performance targets in a long term partnership agreements.

- Set-Based Concurrent Engineering $(S B C E)$ : the most central element of Lean PD is set based engineering [6], [9], and [10]. SBCE is a design paradigm that revolutionizes PD process from structural and task based development to knowledge based development. Traditionally, designers decide to choose a single design concept to develop, among many potential concepts, as early as possible without having sufficient knowledge that the selected concept will be feasible and optimal [6]. In SBCE paradigm, multiple alternative conceptual solutions for a component/module/full-product will be explored and developed early based on proven data and knowledge. Concepts are progressively eliminated once more knowledge about product, process and customers are known. In this way, SBCE creates a planned flexibility in a PD for expected and unexpected uncertainties. Moreover, it enables Toyota to reduce design iterations and foster innovation [6], [9], and [10]. 
The Lean PD elements mentioned above are enablers for industries to reduce wastes and focus on value creating activities. Researches show that product developers spend only $12 \%$ of the time creating value, $11 \%$ on necessary but non value adding activities, and $77 \%$ of the time is wasted on activities that add no value [12]. The central problems are not designers or project managers but it is the way PD is structured and managed [6].

Although the detail discussion of each lean element is beyond the scope of the paper, the introductions make a foundation for the discussions that follow in this paper. In section 2, the gaps in adopting the elements across Italian Industries will be discussed. Section 3 presents the rationale behind developing learning methodologies to increase the awareness and the adoption level of Lean PD. In section 4, the two learning instruments/methodologies that are developed will be presented as cases. Finally, in section 5 conclusions and future plans will be discussed.

\section{Gaps between in Application}

Are companies aware about Lean PD concepts? Are they applying Lean PD elements within their development processes? In order to answer these questions and investigate the gap between theory and application, a field study was undertaken [15]. Fourteen Italian companies were asked to share the knowledge and maturity level of implementation of the Lean PD. The results of the investigation are discussed as follows:

- Chief Engineer (CE) System: more than half of the interviewed companies (59\%) has a non-technical leader to manage projects. On the contrary, the rest $41 \%$ recognizes the importance of having a technical leader. However, cost and performance target definitions based on a deep customer value analysis is still up to nontechnical leaders across the industries.

- Cross Functional Knowledge Capturing, Using and Reusing: the importance to have proven knowledge for decision making in PD process is considered very important among the $62 \%$ of the companies. However, the ways in which knowledge are documented and reused are far from being lean. In fact, knowledge is captured in $94 \%$ of the cases using verbal communication. In order to share and reuse knowledge most company use extensive reports (46\% of cases) and experts' personal judgment (47\% of cases). Only in $19 \%$ of the cases, lesson learned documents are reused for future projects. None of the companies interviewed use limit and tradeoff curves.

- Simultaneous Engineering (SE): the concept of Module Development Team is not so diffused in Italian companies. In fact only in $31 \%$ of cases, manufacturing engineers provide design constraints to design engineers before design solutions are prepared. In most of cases $(50 \%)$ manufacturing engineers are involved after concept selection. The sharing of up-to-date or real time information and status about projects using Obeya rooms is only followed by one company.

- Standardization and Reusing (Product Variety Management): standardization and reusing parts are used by $1 / 3$ of the cases. In designing new products, previous 
platforms are re-used in most of cases (72\%). But, often re-using causes poor product differentiation and low level of innovation. Only one company implements optimized Product Variety Management approaches.

- Supplier Involvement: a proactive involvement of suppliers during PD process is low within the interviewed companies. Only $11.8 \%$ of companies is informed by their suppliers on what they can provide. In $64.7 \%$ of the cases, suppliers are not involved at all in concept development and are requested to provide one concept solution, based on already pre-defined specifications. Communication between companies and suppliers is not frequent and continuous.

- Set-Based Concurrent Engineering: the concept of SBCE, as described and used by Toyota, is not diffused in Italian companies. In very few cases $(11 \%)$, multiple solutions for each product/component are designed and ruled out as more information becomes available (due to prototyping, testing, integration etc.). In most cases (89\%), even if concurrent engineering is in some way considered, only one solution is quickly frozen and designed. The SBCE paradigm is still unknown by the majority of designers. The same is true for front loading process. Companies are still following the norm of "firefighting" at the end of a project than investing resources early to explore the feasibilities and risks of alternative conceptual designs.

\section{Learning Methodologies towards Lean PD Application}

As discussed in Section 2, the adoption level of the Lean PD elements is at a fledgling stage. Although several reasons can be attributed to the causes, the level of awareness about the elements can be taken as a significant inhibitor. The level of awareness means that: i) the meaning of each Lean PD element is new to companies, ii) how to implement those elements might be unclear, and iii) the advantages of each Lean PD elements are not well understood. To fill the awareness gaps, developing learning methodologies ${ }^{1}$ sought to be important. According to Knight [13], innovation potential of an organization depends on the learning approaches exerted to introduce a new working method. In our case, Lean PD has a great potential to improve PD performances. However, companies are not yet aware how to adopt Lean PD systematically.

Serious games are one way of facilitating learning. Serious game is defined as "Entertaining games with non-entertainment goals" [14]. The aim of developing a serious game is to create a hand-on experience to participants to learn a certain issue. The engaging power of serious games brings participants' attention on the learning, and facilitates discussion among participants as a consequence. In this paper, two serious games, developed by the authors, will be presented. The first one is called "MyWaste". This game is used to identify and prioritize PD wastes, and further create opportunities to brainstorm possible continuous improvement activities in a bottomup fashion. The second one is called "Lean PD Game". This computer-based serious game aims at introducing the Lean PD elements in an engaging manner. Both serious

1 In this paper, the terms learning methodology and serious game are used interchangeably to refer MyWaste and Lean PD game. However, in stricter sense MyWaste should not be taken as a serious game as the Lean PD game. 
games have been validated across industries in Italy and Spain. The details about the games and the validation are presented in the following sections.

\section{Cases (MyWaste and Lean PD Game)}

\subsection{MyWaste}

MyWaste is a learning tool developed to support practitioners on how to deal with wastes in PD [16]. It can be used by designers, engineers and project managers. Players will be able to: (i) understand what are wastes in PD, (ii) measure the impact of each waste on PD performances (cost, time and quality), and (iii) identify focus areas for improvements.

MyWaste is structured in a check-list form, contains a library of 33 possible wastes designers might face during their daily activities. For example, time spent on reworks and revisions due to changing priorities, information, data, requirements; reworks and revisions derived by poor-quality products; and inability to reuse previous knowledge etc. Players has to understand the meaning of each waste by, i) trying to translate the waste in real cases, ii) analyzing the possible effects of each waste, iii) brainstorming on the causes/sources of each waste, and iv) evaluating possible way to detect the waste inside a PD process. Then, for each waste, four indicators will be estimated (1-4 scale), see Table 1 as an example:

- Probability $(P)$ : How frequently a waste occurs in PD? Never/Rarely (1), Sometimes (2), Often (3) and Always (4).

- Severity $(S)$ : How much a waste represents a problem for the company? Unimportant (1), A Little (2), Enough (3) and Very Much (4).

- Detectability $(D)$ : How easy it is to detect a waste in a process? Very Easy (1), Easy Enough (2), Hard Enough (3) and Impossible (4).

- Avoidability (A): Is it possible to avoid the waste? Not Avoidable Waste (1), Difficult to Avoid Waste (2), Quite Avoidable Waste (3), and Avoidable Waste (4).

By multiplying these four indicators, a Priority Index of Intervention (PII) can be determined for each waste. Using PII, it is possible to measure and rank wastes, identifying those that have significant impacts on performances, and to create opportunities to reduce and/or eliminate wastes at the source. Playing MyWaste allows designers to be aware of the activities that do not generate value. Moreover, by playing MyWaste continuously, management will be able to identify priority areas for continuous improvement actions.

Not only the literature analysis has showed lacks about waste measurement methods, but also the field study introduced in section 2 resulted in an explicit need for a tool able to teach practitioners what are wastes and how they can affect the PD performances. MyWaste was built with the goal to fill this gap and to validate it across industries. 
Table 1. Check-list example

\begin{tabular}{|c|c|c|c|c|c|c|c|c|c|c|}
\hline Description & $\begin{array}{l}\text { Waste } \\
\text { Macro-class }\end{array}$ & $\mathbf{P}$ & $\mathbf{S}$ & D & $\mathbf{A}$ & PII & $\begin{array}{l}\text { Waste } \\
\text { Potential } \\
\text { Effect }\end{array}$ & $\begin{array}{l}\text { Waste Potential } \\
\text { Cause }\end{array}$ & $\begin{array}{l}\text { Detection } \\
\text { Way }\end{array}$ & $\begin{array}{l}\text { Recommendable Corrective } \\
\text { Actions }\end{array}$ \\
\hline \multirow{2}{*}{$\begin{array}{l}\text { Time is } \\
\text { spent for } \\
\text { reworks and } \\
\text { revisions due } \\
\text { to changing } \\
\text { priorities, } \\
\text { information, } \\
\text { data, } \\
\text { requirements }\end{array}$} & \multirow[b]{2}{*}{$\begin{array}{l}\text { Processing } \\
\text { (Over } \\
\text { Inappropriate) }\end{array}$} & & & \multirow[b]{2}{*}{2} & \multirow[b]{2}{*}{3} & \multirow[b]{2}{*}{96} & \multirow{2}{*}{$\begin{array}{l}\text { Increasing } \\
\text { development } \\
\text { costs and } \\
\text { times }\end{array}$} & $\begin{array}{l}\text { A detailed analysis } \\
\text { on customers' } \\
\text { needs is missing, } \\
\text { or because we } \\
\text { didn't do it or } \\
\text { because our } \\
\text { customer didn't } \\
\text { understand its } \\
\text { customers' needs. }\end{array}$ & \multirow{2}{*}{$\begin{array}{l}\text {-Consider the } \\
\text { number of } \\
\text { modifications } \\
\text { done } \\
\text {-Lesson } \\
\text { Learned to } \\
\text { understand } \\
\text { the causes of } \\
\text { the modifica- } \\
\text { tions } \\
\text {-Project } \\
\text { review / } \\
\text { project } \\
\text { portfolio } \\
\text { review } \\
\text { Audit }\end{array}$} & $\begin{array}{l}\text {-Introduce a strong and } \\
\text { effective methodology to } \\
\text { understand customers' needs } \\
\text { and to assign priorities (formal- } \\
\text { ize a communication to discuss } \\
\text { product specifications between } \\
\text { designer and customer) }\end{array}$ \\
\hline & & 4 & 4 & & & & & $\begin{array}{l}\text { Marketing } \\
\text { department/central } \\
\text { direction has } \\
\text { decided that the } \\
\text { priorities have } \\
\text { changed, due to } \\
\text { new opportunities } \\
\text { coming or some } \\
\text { changes in the } \\
\text { value chain } \\
\text { perspective. }\end{array}$ & & $\begin{array}{l}\text {-Introduce a tool to manage } \\
\text { project portfolio }\end{array}$ \\
\hline $\begin{array}{l}\text { Reworks and } \\
\text { revisions } \\
\text { derived by } \\
\text { poor-quality } \\
\text { products; }\end{array}$ & $\ldots$ & & & & & & $\ldots .$. & $\cdots$ & ..... & $\cdots$ \\
\hline$\ldots \ldots$ & $\ldots$ & & & & & & $\ldots \ldots$ & $\ldots$ & $\ldots$ & $\ldots \ldots$ \\
\hline
\end{tabular}

The game has been validated in 10 Italian companies, by more than 40 participants from different industrial sectors with the result shown in Figure 2. Simplicity and intuitiveness are MyWaste's main advantages. Industries can also use it as a benchmark mechanism to compare themselves with other industries. MyWaste should be used as a team exercise. Different functional teams can use it to communicate inefficiencies in a product development process.

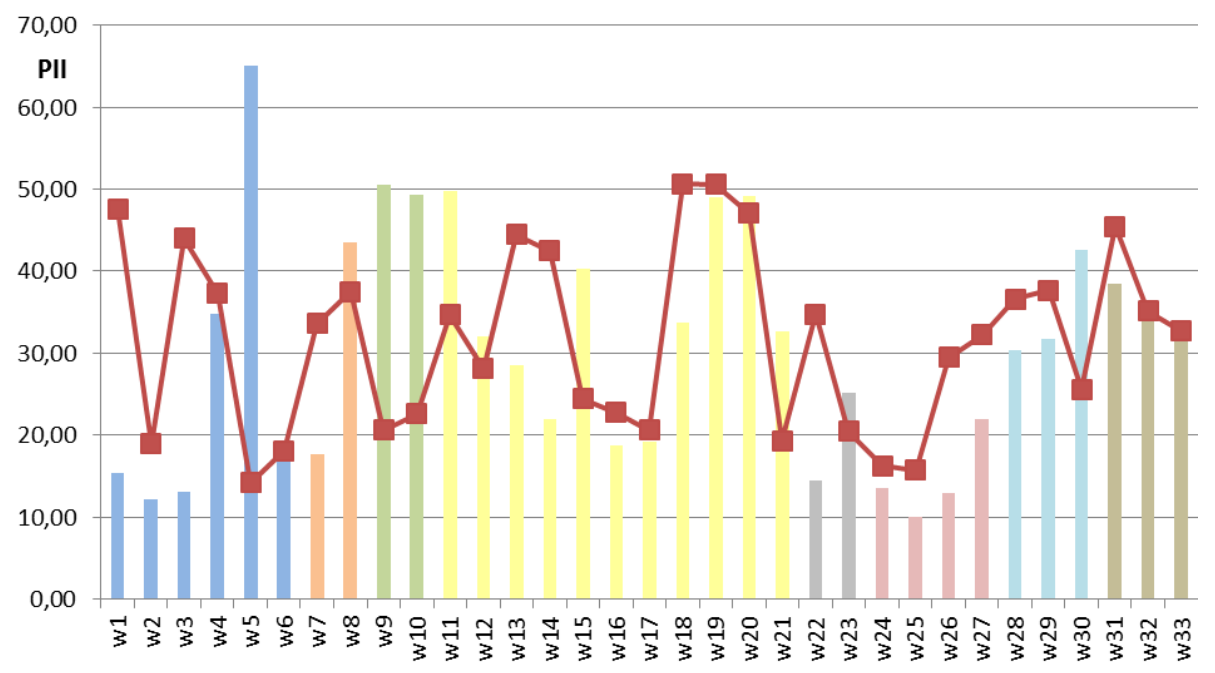

Fig. 2. Waste prioritization example (Note: $\mathrm{W}$ indicate a waste sub-category) 


\subsection{Lean PD Game}

MyWaste can be used to diagnose a process, but it doesn't give a hand-on experience on how to make a PD process better. The Lean PD game is a computer based serious game designed to create a learning environment for applying Lean PD elements systematically while developing a simplified airplane structure. Given a set of customer requirements, players should design an airplane on a given design table. Each player will act as a company who wants to satisfy the customer. The airplane should have four sub-systems; body, wing, tail and cockpit. Players should use supplier catalogues to build the subsystems of the airplane.

The game is divided into two stages; first and second. In the first stage, players will use their primarily knowledge to build an airplane needed. This stage simulates the traditional PD environment where players will not have any supporting Lean PD element to make their design decisions. Once players completed a prototype design, they should submit to "testing department" to check for stability, flying conditions and dimensional configurations. If it fails, the prototype should be redesigned. Redesigning has penalty costs. If the prototype passes the testing constraints, players will be given the breakdown of their performances in terms of quality, time and cost. The comparison between customer requirements and a player's performance will be given as an aggregate value called "Lean score".

In the second stage, players supported systematically by the Lean PD elements. This stage is divided into phases to lead players in a Lean PD environment and arrive to optimal airplane at a lower cost and time than the first stage. As shown in Figure 3, each phase is supported by different lean technique/s to create the Lean PD environment. Below, each phases of the game is briefly explained:

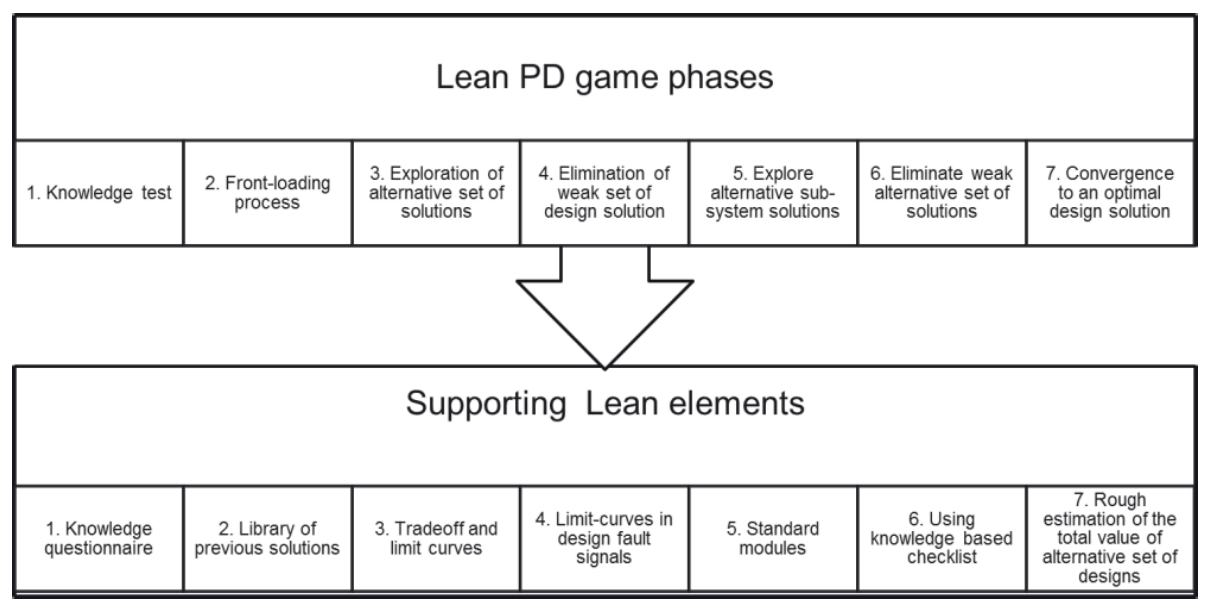

Fig. 3. Lean PD game phases (Stage 2) and supporting lean elements

- Knowledge test: at beginning of the game "the chief engineer (CE)" questions about the aeronautics knowledge of players in the form of multiple choice questions. This equips players to have the right previous knowledge before designing 
an airplane. Moreover, the $\mathrm{CE}$ guides players to understand better the customer requirements.

- Front loading process: at this phase, player will be provided with airplane models which are already in a knowledge library. These help players to compare what have already been designed by other designers before, so as not to waste time creating from scratch.

- Explore alternative set of solutions: at this phase, players will be supported by "tradeoff-curves" to explore alternative sub-system solutions and able to ingrate customer requirements into an airplane design parameters. This phase is the beginning of a SBCE process in the game.

- Elimination of weak solutions: players at this phase can eliminate airplane's subsystem solutions that are proved to be infeasible. Here, players supported by the so called "limit-curves" that show the feasibilities of the design alternatives early in the PD process.

- Explore alternative solutions: the above phases help players to come up with feasible bodies and wings. For each alternative body and wing solutions players can use standard cockpits and tails to prototype alternative airplanes. In a way, they are introduced with one of the Lean PD element (Product variety management through reusing and standardization).

- Eliminate weak alternative airplane solutions: at this phase, player has alternative airplane solutions which should be evaluated against pre-prepared knowledge from "testing department" in the form of checklist. This checklist uses to classify full airplane design solutions as "safe" and "risky".

- Convergence to optimal solution: once alternative feasible airplanes are found, cross functional information from manufacturing, assembly, and supplier will be visible in a real time basis to estimate the cost and development time of each airplane solutions. Moreover, visual charts are provided to show a rough estimation of the aggregate "Lean score" values of each designs to support decision making.

Finally, the detail performance comparison of the two stages will appear for discussion among participants in the game.

Lean PD Game has been validated among industries and engineering classes in Italy and Spain. In total, about 80 participants have participated in the validation. To evaluate the success of the Lean PD elements in the second stage of the game, an average percentage improvement of playing time, development time and cost are taken. The comparison is between first and second stages of the game or non-Lean PD with Lean PD. According to the results, in average, players improve playing time by $55 \%$, development time by $45 \%$ and development cost by $43 \%$. This shows that, Lean elements enable players to quickly converge into an optimal airplane that satisfies a given set of customer requirements.

Garris model has been used to evaluate the improved level of awareness about Lean PD using the game [17]. Garris et.al. describe three aspects to measure the effectiveness of a serious game in attaining a predefined objectives. Declarative knowledge, targeted at measuring if the game increases the domain understanding of players; Procedural knowledge, aims at learning of procedures, and also to the under- 
standing of patterns of processes and behavior; Strategic knowledge, finally this aspect refers to if players get knowledge to translate concepts from game to real application problem. Based on the above framework, a structured questionnaires based on the Likert five scale model is developed. Players form different industry have been asked immediately after playing it. Figure 4 shows the result of the survey concerning the declarative knowledge of the Lean PD game.

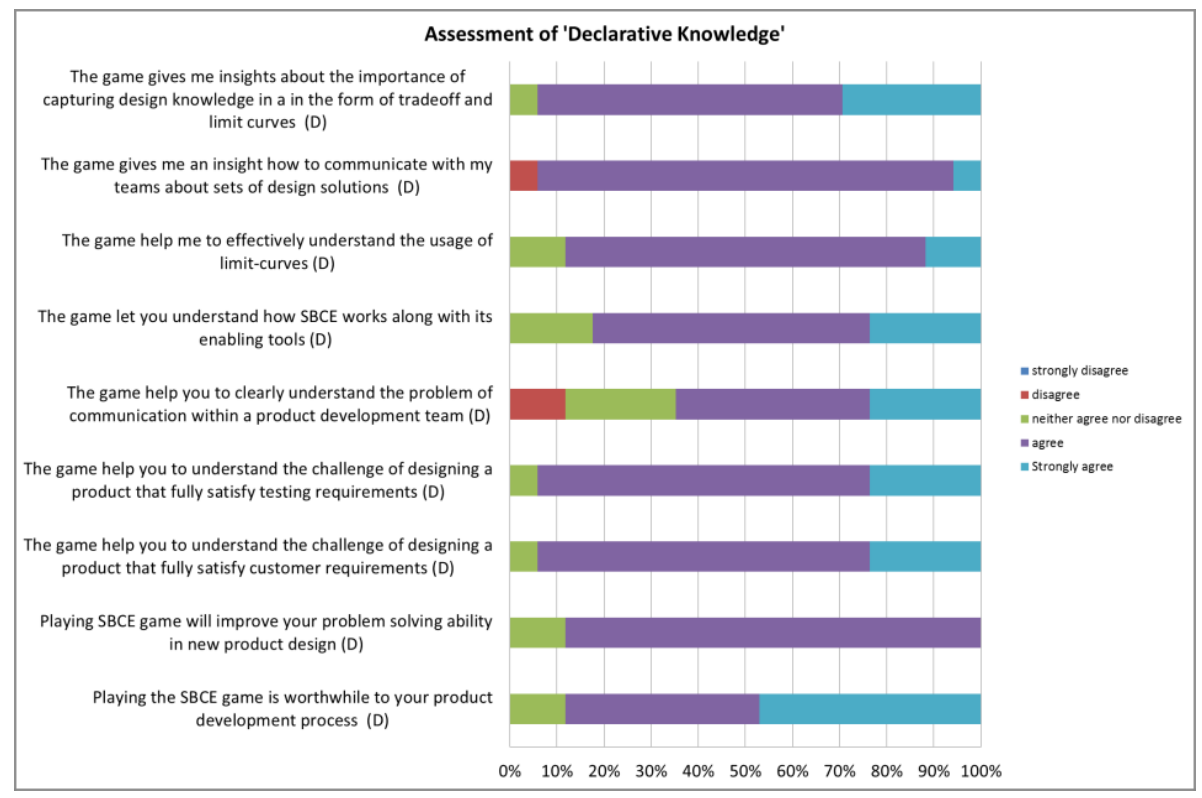

Fig. 4. Assessment of the declarative knowledge

As shown in the figure above, the game has been effective in translating the theory to practitioners. Most of the players agreed that playing the game give them a good level of understanding on how to explore alternative solutions and communicate among the teams using the provided Lean PD elements. Similarly, players been asked to relate the Lean PD elements and their possible impacts on PD performance improvements.

Figure 5 shows the procedural knowledge assessment in terms of players' perceived improvements of the Lean PD elements embedded in the game. The theoretical advantages of Lean PD seems to be confirmed by the practitioners. Most of the designers played the game agreed that the most significant perceived advantages are 'facilitate learning about design solutions' and 'avoid design risks'. Using knowledge from past designs and exploration of alternative designs enable the PD teams to brainstorm about set of solutions rather than one alternative. Moreover, frontloading the PD process minimize the probability of 'false positive feasibility' to occur. False positive feasibility is a major problem in industry, and it refers to a phenomena where project teams assume a concept is feasible, but will learn later in the development process that it is not. 


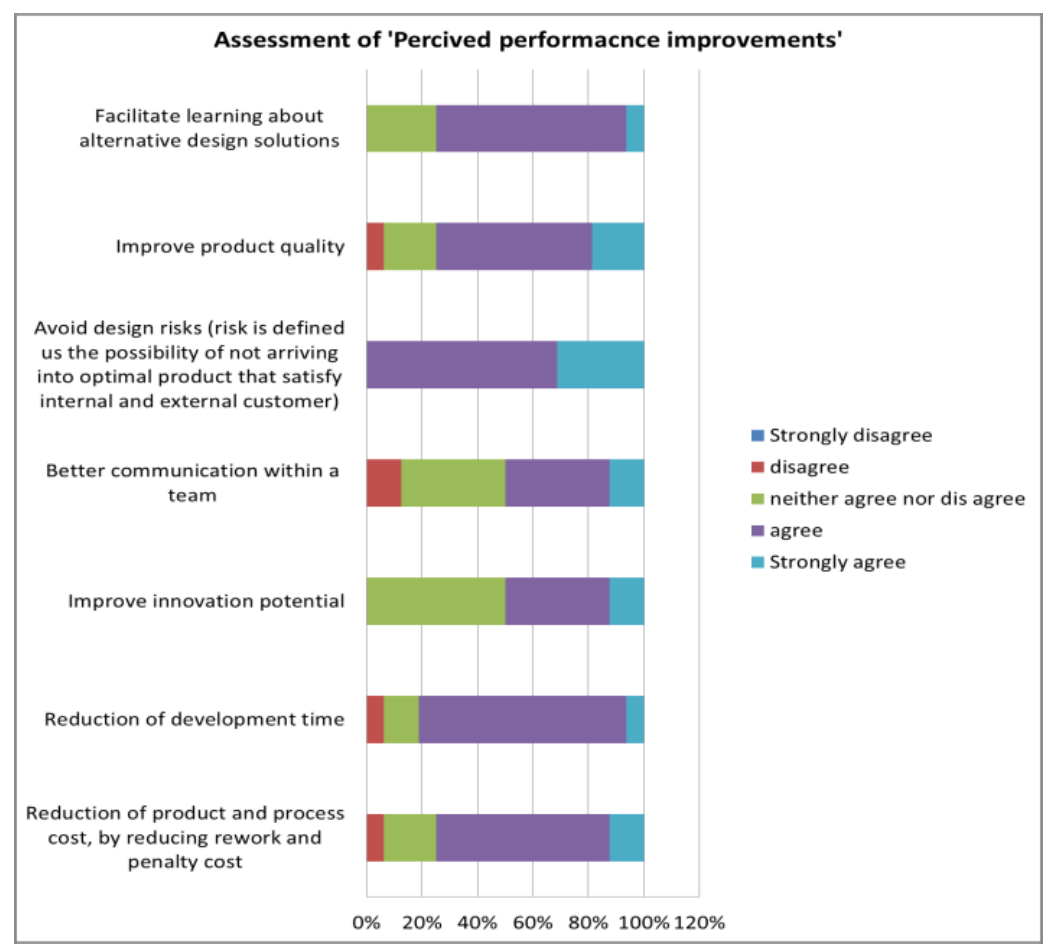

Fig. 5. Assessment of the 'perceived performance improvement' of applying lean in PD

\section{$5 \quad$ Conclusion and Future Work}

As clearly showed in section 1, traditional PD results in a series of inefficiencies, for example long development time, high design cost, unnecessary reworks and iterations. The application of Lean principles and techniques to PD allows encompassing these problems by fostering knowledge sharing and re-using, customer value capturing, concurrent product development, SBCE process, and so on. Toyota is very well aware about how to implement the elements in order to gain competitive advantage. But the level of maturity and awareness of applying these elements is in other companies (at least in Italy) are not well developed or systematized.

Learning approaches are crucial in creating awareness on the importance of applying Lean PD elements in order to obtain improved performances. The two serious games proposed by the authors are to facilitate learning and improvement, creating a hand-on experience to participants to learn the Lean PD benefits.

The games have been tested and validated in both Italian and some European companies. The level of awareness about the elements has been improved, and the feedback obtained from the validation is encouraging.

The research will continue to validate the methodologies across other industries and countries to build more robust learning methodologies for adopting Lean PD elements in industries. 
Acknowledgments. This work was partly funded by the European Commission through the project Lean Product and Process Development - LeanPPD (NMP-2008214090, www.leanppd.eu) and the network of excellence Games and Learning Alliance GALA (ICT-2009-258169, www.galanoe.eu). The authors wish to acknowledge their gratitude and appreciation to the rest of the project partners for their contributions during the development of various ideas and concepts presented in this paper.

\section{References}

1. Chesbrough, H.W.: The era of open innovation. MIT Sloan Management Review 44(3), 35-41 (2003)

2. Chesbrough, H., Vanhaverbeke, W., West, J.: Open Innovation: Researching a New Paradigm. Oxford University Press, New York (2006)

3. Womak, J.P.: Lean thinking: Banish waste and create wealth in your corporation. Simon \& Schuster, New York (1996)

4. Womack, J.P., Jones, D.T.: Lean Thinking-Banish Waste and Create Wealth in Your Corporation, 2nd edn. Simon and Schuster New York (2003)

5. Morgan, J.M., Liker, J.K.: The Toyota Product Development System: Integrating People, Process, and Technology. Productivity Press, New York (2006)

6. Ward, A.C., Shook, J., Sobek, D.K.: Lean Product and Process Development. The Lean Enterprise Institute, Cambridge, Massachusetts (2007)

7. Balle, F., Balle, M.: Lean Development. Business Strategy Review 16, 17-22 (2005)

8. Haque, B., James-Moore, M.: Applying Lean Thinking to New Product Introduction. J. of Engineering Design 15(1), 1-31 (2004)

9. Ward, A., Liker, J.K., Cristiano, J.J., Sobek II, D.K.: The Second Toyota Paradox: How Delaying Decisions Can Make Better Cars Faster. Sloan Management Review 36, 43-61 (1995)

10. Sobek, D.K., Ward, A.C., Liker, J.K.: Toyota's Principles of Set-Based Concurrent Engineering. Sloan Management Review 40, 67-83 (1999)

11. Oppenheim, B.W.: Lean Product Development Flow. Systems Engineering 7(4), 352-378 (2004)

12. Oehmen, J., Rebentisch, E.: Waste in Lean Product Development. LAI Paper Series on Lean Product Development for Practitioners, Lean Advancement Initiative (LAI), Massachusetts Institute of Technology (2010)

13. Knight, J.: Trade in Higher Education Services: The Implications the General Agreement on Trade in Services (GATS). The Observatory on borderless higher education (2002), http: / /www. obhe.ac.uk

14. Raybourn, E.M., Deagle, E., Mendini, K., Heneghan, J.: Adaptive Thinking \& Leadership Simulation Game Training for Special Forces Officers. In: I/ITSEC 2005 Proceedings, Interservice/ Industry Training, Simulation and Education Conference Proceedings, Orlando, Florida, USA, November 28-December 1 (2005)

15. Rossi, M., Kerga, E., Taisch, M., Terzi, S.: Lean Product Development: Fact Finding Research in Italy. In: International Conference on Industrial Engineering and Systems Management (IESM) Proceedings, Metz (France), May 25-27 (2011)

16. Rossi, M., Kerga, E., Taisch, M., Terzi, S.: Proposal of a method to systematically identify wastes in New Product Development Process. In: IEEE Proceeding of the 7th International conference on Concurrent Enterprise (ICE 2011), Aachen, Germany, June 20-22 (2011)

17. Garris, R., Ahlers, R., Driskell, J.E.: Games, Motivation, and Learning: A Research and Practice Model. Simulation and Gaming 33(4), 441-467 (2002) 